\title{
ESTIMATIVA DA IRRADIAÇÃO SOLAR GLOBAL COM PARTIÇÃO MENSAL E SAZONAL PẢRA A REGIÃO DE CASCAVEL - PR ${ }^{1}$
}

\section{MELANIA I. VALIATI ${ }^{2}$, REINALDO P. RICIERI ${ }^{3}$}

RESUMO: No presente trabalho, mostram-se equações de estimativa da irradiação solar global $\left(\mathrm{R}_{\mathrm{G}}\right)$, por meio do modelo de Angstrom, com partições sazonal e mensal para a região de Cascavel - PR. Os dados experimentais foram cedidos pelo IAPAR, coletados na sua estação meteorológica localizada na COODETEC/Cascavel - PR, no período de 1983 a 1998. Dos 16 anos de dados, 12 anos foram utilizados para cálculo dos coeficientes (a e b) e quatro anos para a validação das equações. Os coeficientes de determinação encontrados foram superiores a $80 \%$ para as duas partições. O mínimo da $\mathrm{R}_{\mathrm{G}}$ é superestimado e o máximo é subestimado quando comparados com o mínimo e o máximo para dados reais, sendo esses encontrados no solstício de inverno e equinócio de primavera, respectivamente. A variação sazonal e mensal do coeficiente "a" foi menor (0,16 a 0,19 e 0,14 a 0,21) e do coeficiente "b" maior $(0,34$ a 0,43 e 0,32 a 0,44$)$. As maiores variações dos erros médios diários ocorreram no equinócio de primavera $(-19,45 \%$ a $27,28 \%)$ e as menores no equinócio de outono $(-11,32 \%$ a $10,61 \%)$. O ajuste mais eficaz das equações foi encontrado para a partição mensal.

PALAVRAS-CHAVE: heliógrafo, actinógrafo, modelo de Angstrom.

\section{EVALUATION OF GLOBAL SOLAR IRRADIATION WITH SAZONAL AND MONTHLY PARTITION FOR THE AREA OF CASCAVEL - PR, BRAZIL}

\begin{abstract}
This research shows equations of evaluation of global solar irradiation (GR) through Angstrom's model with seasonal monthly partitions for the region of Cascavel -PR, Brazil. The experimental data were given by IAPAR and collected in its meteorological station located in COODETEC/Cascavel - PR, Brazil, from 1983 to 1998. Twelve of the sixteen years of data were used for calculation of the coefficients ( $a$ and $b$ ) and four years for the validation of the equations. The determination coefficients found were superior to $80 \%$ for both partitions. The minimum (GR) is overestimated and the maximum is underestimated when compared to the minimum and maximum for real data, been these found in the winter solstice and spring equinox, respectively. The seasonal and monthly variation of the coefficient "a" was lower ( 0.16 to 0.19 and 0.14 to 0.21$)$ and the variation for the coefficient " $b$ " was higher $(0.34$ to 0.43 and 0.32 to 0.44$)$. The highest variations of daily average errors had occurred in the spring equinox $(-19.45 \%$ to $27.28 \%)$ and the lowest ones in the autumn equinox $(-11.32 \%$ to $10.61 \%)$. The most efficient adjustment of the equation was found for the monthly partition.
\end{abstract}

KEYWORDS: actinographer, heliographer, model of Angstrom.

\footnotetext{
${ }^{1}$ Extraído da dissertação de Mestrado do primeiro autor .

${ }^{2}$ Doutoranda em Agronomia, UNESP, Botucatu - SP, Profa. MSc., Faculdade e Colégio Integrado de Campo Mourão, melania@grupointegrado.br

${ }^{3}$ Prof. Dr., Curso de Mestrado de Engenharia Agrícola, UNIOESTE - PR.

Recebido pelo Conselho Editorial em:16-9-2002

Aprovado pelo Conselho Editorial em: 28-2-2005
} 


\section{INTRODUÇÃO}

A radiação solar, ao se propagar na atmosfera, até atingir a superfície da Terra, passa pelos processos de espalhamento e absorção. Em conseqüência da razão do espalhamento, observa-se, além da componente direta, a irradiação solar difusa, sendo a soma dessas duas componentes denominada irradiação solar global.

Os tipos de cobertura do céu (nublado, parcialmente nublado e limpo) são determinados por vários pesquisadores de diferentes formas, sem citar a metodologia utilizada. RICIERI (1998) determinou uma metodologia para a obtenção do tipo de cobertura do céu em função do índice de claridade $\left(\mathrm{K}_{\mathrm{t}}\right)$, para a cidade de Botucatu, por meio de comparação gráfica das irradiações global, direta e difusa na incidência horizontal, observando que, no intervalo de $0<\mathrm{K}_{\mathrm{t}}<0,3$, as irradiações global e difusa são praticamente iguais, e a irradiação direta está próxima de zero, classificando o céu nessas condições como nublado. Para $0,3 \leq \mathrm{K}_{\mathrm{t}} \leq 0,65$ as irradiações difusa e direta mantêm-se próximas, denominando-se de céu parcialmente nublado. Para $K_{t}>0,65$, a irradiação direta aproximase da global, enquanto a difusa tende ao mínimo e, nessas condições, denomina-se de céu limpo.

Esse mesmo autor, em 1996, obteve os coeficientes "a" e "b" da equação de Angstrom por meio de uma série de dados, da irradiação medida por piranômetro de alta precisão, na localidade de Botucatu - SP, comparando-os com os encontrados por TUBELIS (1988), que utilizou uma série de dados obtidos por um actinógrafo, na mesma localidade, concluindo que os coeficientes não diferem entre si, mostrando assim que a irradiação medida por actnógrafo pode ser utilizada nos cálculos dos coeficientes de Angstrom.

Realizando um estudo de limite na equação de Angstrom para a região de Cascavel - PR, com partição anual, VALIATI et al. (1999) concluíram que o índice de claridade mínimo é 0,16 e o máximo é 0,56. DANTAS et al. (1999) estudaram esse mesmo fenômeno para duas cidades da Paraíba, verificando para a cidade de Cabaceiras, que o mínimo e o máximo do índice de claridade ocorreram em novembro, estando compreendido entre 0,13 e 0,73; para a cidade de Belém do Brejo do Cruz, o mínimo ocorreu em setembro e o máximo em julho, estando compreendido entre 0,11 e 0,76. SANTOS et al. (1983) encontraram para a cidade de Jaboticabal uma transmissividade máxima de 0,75 para a partição anual; já CURY-LUNARDI \& CATANEO (1994), para a cidade de Botucatu, encontraram 0,67 e 0,71 para primavera-verão e outono-inverno, estando próximo ao encontrado por LAPERUTA FILHO (1996) para a mesma região, obtendo 0,70 para a primavera, 0,72 para o inverno, 0,66 para o outono e 0,65 para o verão.

$\mathrm{O}$ alto custo dos instrumentos e a necessidade de um técnico especializado para a coleta de dados e a manutenção dos equipamentos fizeram com que, em várias regiões, não se tivesse o conhecimento da irradiação solar global. Devido a esse fato, pesquisadores vêm utilizando modelos para estimar esta componente, com boa precisão, relacionando a irradiação solar no topo da atmosfera com a razão de insolação (r). Um dos pioneiros na utilização de modelos para estimativa da irradiação solar global foi ANGSTROM, em 1924, por meio da seguinte equação:

$$
\mathrm{R}_{\mathrm{G}} / \mathrm{R}_{\mathrm{C}}=\alpha+(1-\alpha) \mathrm{r}
$$

em que,

$\mathrm{R}_{\mathrm{G}}$ - irradiação solar global, $\mathrm{MJ} \mathrm{m}^{-2}$;

$\mathrm{R}_{\mathrm{C}}$ - irradiação total sob atmosfera real em dia completamente limpo, $\mathrm{MJ} \mathrm{m}^{-2}$;

$\mathrm{r}$ - razão de insolação $(\mathrm{r}=\mathrm{n} / \mathrm{N}$, sendo: $\mathrm{n}$ o total de horas de brilho solar diária na superfície terrestre em horas e $\mathrm{N}$ o número máximo de brilho solar no topo da atmosfera em horas), e

$\alpha$ - fração da irradiação recebida em um dia completamente nublado pela medição em dia completamente limpo. 
Devido à dificuldade na medição de $\mathrm{R}_{\mathrm{C}}$, a qual deve ser medida em dias de céu limpo, não ocorrendo com freqüência em muitas regiões, PRESCOTT (1940) correlacionou a irradiação solar encontrada na superfície da Terra com a encontrada no topo da atmosfera $\left(\mathrm{R}_{\mathrm{O}}\right)$, obtida por meio do uso de equação, a qual, mesmo após a modificação, continua sendo chamada pelos pesquisadores de equação de Angstrom, ou seja:

$$
\left(\mathrm{R}_{\mathrm{G}} / \mathrm{R}_{\mathrm{O}}=\mathrm{a}+\mathrm{b} \mathrm{r}\right)
$$

em que,

"a" e "b" - coeficientes da equação de Angstrom.

Os coeficientes "a" e "b" da equação são calculados mediante o uso de regressão linear, utilizando-se de dados diários quinzenais, mensais, sazonais, anuais e recentemente DAL PAI \& ESCOBEDO (1999) vêm estudando a partição instantânea (ou 5 minutos).

Mediante o exposto, este trabalho teve como objetivo a determinação dos parâmetros da equação de Angstrom com partição mensal e sazonal para a estimativa da irradiação solar global diária, na região de Cascavel - PR.

\section{MATERIAL E MÉTODOS}

Os dados de 1983 a 1998 foram fornecidos pelo Instituto Agronômico do Paraná (IAPAR), Londrina - PR, coletados em sua estação meteorológica localizada na Cooperativa Central Agropecuária de Desenvolvimento Tecnológico e Econômico Ltda. (COODETEC), Cascavel - PR, localizada na BR $467 \mathrm{~km} \mathrm{98}$, com latitude de $24^{\circ} 53^{\prime} \mathrm{S}$, longitude de $53^{\circ} 23^{\prime} \mathrm{W}$ e altitude de $682 \mathrm{~m}$.

A estação meteorológica estava localizada em terreno plano, com boa visão do horizonte. Os dados foram obtidos diariamente do nascer ao pôr-do-sol, durante 16 anos, sendo as medidas da irradiação solar global obtidas por um actinógrafo (R.FUESS - BERLIN - STEGLITZ) e o total de horas de brilho solar diária incidente na superfície da Terra (n), por heliógrafo (R.FUESS - BERLIN STEGLITZ).

Elaborou-se um programa computacional em BASIC, para os cálculos da declinação solar $(\delta)$, ângulo horário $\left(\mathrm{W}_{\mathrm{S}}\right)$, fator de correção da excentricidade da órbita terrestre $\left(\mathrm{E}_{\mathrm{o}}\right)$, irradiação no topo da atmosfera $\left(R_{o}\right)$ e cálculo da razão de insolação (r), sendo essas equações citadas por IQBAL (1983). Os resultados gerados pelo programa foram inseridos em planilhas do programa "Sofware Microcal Origin", ao lado dos dados experimentais referentes aos respectivos dias.

Da série de 16 anos de dados (1983 a 1998), 12 anos (1983 a 1994) foram utilizados para o cálculo dos coeficientes (a e b) da equação de Angstrom, separando-os com partições sazonal e mensal. Essa separação ocorreu da seguinte forma: a) partição sazonal: separaram-se os dados do dia 23 de setembro a 20 de dezembro para o equinócio de primavera; 21 de dezembro a 20 de março para o solstício de verão; 21 de março a 21 de junho para o equinócio de outono, e 22 de junho a 22 de setembro para o solstício de inverno, para os doze anos. Nas figuras, essas datas estão representadas pelo calendário juliano, ou seja: equinócio de primavera do dia juliano 267 a 355; solstício de verão do dia juliano 356 a 80; equinócio de outono do dia juliano 81 a 173 e solstício de inverno do dia juliano 174 a 266, e b) partição mensal: separaram-se os dados do primeiro ao último dia de cada mês, totalizando uma série de 12 meses, de janeiro a dezembro. Em seguida, foi realizada uma comparação entre os valores estimados e reais com base nos erros médios (eq.3), sendo esses apresentados em forma de figura:

$$
\Delta(\%)=100\left(\left(\mathrm{R}_{\mathrm{Gmed}}-\mathrm{R}_{\mathrm{Gest}}\right) / \mathrm{R}_{\mathrm{Gmed}}\right)
$$

em que, 
$\mathrm{R}_{\mathrm{Gmed}}$ - irradiação solar global medida, $\mathrm{MJ} \mathrm{m}^{-2}$, e

$\mathrm{R}_{\text {Gest }}$ - irradiação solar global estimada, $\mathrm{MJ} \mathrm{m}^{-2}$.

Para o cálculo das médias dos erros, foi utilizado o módulo dos erros médios diários $(|\Delta(\%)|)$.

\section{RESULTADOS E DISCUSSÃO}

\section{Equações encontradas}

\section{Partição sazonal}

Na Tabela 1, são apresentadas as equações de Angstrom, os seus respectivos coeficientes "a" e "b" e coeficientes de determinação $\left(\mathrm{R}^{2}\right)$, apresentando variação de $84 \%$ a $88 \%$ para as quatro estações, mostrando boa precisão nas equações encontradas. Houve menor variação do coeficiente "a" $(0,16$ a $0,19)$ e maior para o coeficiente "b" $(0,34$ a 0,43$)$, ocorrendo aumento do coeficiente "b" no equinócio de outono e solstício de inverno, acontecendo o inverso com o coeficiente "a".

TABELA 1. Equações de Angstrom $\left(\mathrm{K}_{\mathrm{t}}=\mathrm{a}+\mathrm{b} \mathrm{r}\right)$ e coeficientes de determinação $\left(\mathrm{R}^{2}\right)$, para partição sazonal.

\begin{tabular}{cccc}
\hline Número de Dias Observados & Estações & Equações & $\mathrm{R}^{2}(\%)$ \\
\hline 1.078 & Primavera & $\mathrm{K}_{\mathrm{t}}=0,16+0,39 \mathrm{r}$ & 88 \\
1.066 & Verão & $\mathrm{K}_{\mathrm{t}}=0,19+0,34 \mathrm{r}$ & 84 \\
1.073 & Outono & $\mathrm{K}_{\mathrm{t}}=0,16+0,40 \mathrm{r}$ & 87 \\
1.103 & Inverno & $\mathrm{K}_{\mathrm{t}}=0,15+0,43 \mathrm{r}$ & 88 \\
\hline
\end{tabular}

Fazendo um estudo de limite nas equações da Tabela 1, determinaram-se os valores dos índices de claridade $\left(\mathrm{K}_{\text {tmín }}\right.$ e $\left.\mathrm{K}_{\text {tmáx }}\right)$ apresentados na Tabela 2. Observa-se maior e menor incidência da irradiação solar na superfície terrestre local para o período de inverno, estando compreendida entre $15 \%$ e $58 \%$ da irradiação solar incidente no topo da atmosfera. A máxima incidência para o período de inverno também foi observada para a cidade de Botucatu por LAPERUTA FILHO (1996).

TABELA 2. Índices de claridade mínimos $\left(\mathrm{K}_{\mathrm{tmin}}\right)$ e máximos $\left(\mathrm{K}_{\mathrm{tmax}}\right)$ observados por meio das equações de Angstrom, para partição sazonal.

\begin{tabular}{ccc}
\hline Estações & $\mathrm{K}_{\mathrm{tmín}}$ & $\mathrm{K}_{\mathrm{tmáx}}$ \\
\hline Primavera & 0,16 & 0,55 \\
Verão & 0,19 & 0,53 \\
Outono & 0,16 & 0,56 \\
Inverno & 0,15 & 0,58 \\
\hline
\end{tabular}

\section{Partição mensal}

Na Tabela 3, apresentam-se as equações de Angstrom $\left(K_{t}=a+b r\right)$, os seus respectivos coeficientes "a" e "b" e coeficientes de determinação $\left(\mathrm{R}^{2}\right)$, variando entre $82 \%$ e $90 \%$. Houve menor variação do coeficiente "a" $(0,14$ a 0,21$)$ e maior do coeficiente "b" $(0,32$ a 0,44$)$. Observa-se que, quando o coeficiente " $b$ " aumenta, o coeficiente "a" diminui e vice-versa. Houve maior aumento do coeficiente "b" para os meses de maio, junho, julho, agosto, setembro e outubro, não ocorrendo o mesmo com o coeficiente "a".

Fazendo um estudo de limite nas equações da Tabela 3, determinaram-se os valores dos índices de claridade $\left(\mathrm{K}_{\mathrm{tmín}}\right.$ e $\left.\mathrm{K}_{\mathrm{tmáx}}\right)$ apresentados na Tabela 4. Observa-se menor índice de claridade nos meses de maio, julho e setembro, e maior no mês de julho, estando compreendida entre $14 \%$ e $58 \%$ da 
irradiação incidente no topo da atmosfera. A maior incidência para o mês de julho também foi observada para a cidade de Belém do Brejo do Cruz, na Paraíba, por DANTAS (1999).

TABELA 3. Equações de Angstrom $\left(k_{t}=a+b r\right)$ e coeficientes de determinação $\left(R^{2}\right)$, para partição mensal.

\begin{tabular}{cccc}
\hline Número de Dias Observados & Meses & Equações & $\mathrm{R}^{2}(\%)$ \\
\hline 368 & janeiro & $\mathrm{K}_{\mathrm{t}}=0,19+0,33 \mathrm{r}$ & 85 \\
338 & fevereiro & $\mathrm{K}_{\mathrm{t}}=0,21+0,32 \mathrm{r}$ & 82 \\
372 & março & $\mathrm{K}_{\mathrm{t}}=0,18+0,36 \mathrm{r}$ & 84 \\
334 & abril & $\mathrm{K}_{\mathrm{t}}=0,16+0,37 \mathrm{r}$ & 84 \\
358 & maio & $\mathrm{K}_{\mathrm{t}}=0,14+0,42 \mathrm{r}$ & 90 \\
356 & junho & $\mathrm{K}_{\mathrm{t}}=0,16+0,41 \mathrm{r}$ & 86 \\
370 & julho & $\mathrm{K}_{\mathrm{t}}=0,14+0,44 \mathrm{r}$ & 89 \\
365 & agosto & $\mathrm{K}_{\mathrm{t}}=0,15+0,42 \mathrm{r}$ & 88 \\
357 & setembro & $\mathrm{K}_{\mathrm{t}}=0,14+0,43 \mathrm{r}$ & 90 \\
371 & outubro & $\mathrm{K}_{\mathrm{t}}=0,15+0,41 \mathrm{r}$ & 88 \\
359 & novembro & $\mathrm{K}_{\mathrm{t}}=0,16+0,38 \mathrm{r}$ & 89 \\
372 & dezembro & $\mathrm{K}_{\mathrm{t}}=0,18+0,35 \mathrm{r}$ & 87 \\
\hline
\end{tabular}

TABELA 4. Índices de claridade mínimos $\left(\mathrm{K}_{\mathrm{tmín}}\right)$ e máximos $\left(\mathrm{K}_{\mathrm{tmáx}}\right)$ observados por meio das equações de Angstrom, para partição mensal.

\begin{tabular}{ccc}
\hline Meses & $\mathrm{K}_{\mathrm{tmín}}$ & $\mathrm{K}_{\text {tmáx }}$ \\
\hline janeiro & 0,19 & 0,52 \\
fevereiro & 0,21 & 0,53 \\
março & 0,18 & 0,54 \\
abril & 0,16 & 0,53 \\
maio & 0,14 & 0,56 \\
junho & 0,16 & 0,57 \\
julho & 0,14 & 0,58 \\
agosto & 0,15 & 0,57 \\
setembro & 0,14 & 0,57 \\
outubro & 0,15 & 0,56 \\
novembro & 0,16 & 0,54 \\
dezembro & 0,18 & 0,53 \\
\hline
\end{tabular}

\section{Validação do modelo}

\section{Partição sazonal}

$\mathrm{Na}$ Tabela 5, são apresentadas as médias dos valores reais $\left(\mathrm{R}_{\mathrm{Greais}}\right)$ e estimados $\left(\mathrm{R}_{\mathrm{Gest}}\right)$ da irradiação solar global, médias dos erros $(|\Delta|)$ e desvios-padrão médios (S) no período de validação do modelo. A menor incidência da irradiação solar global estimada e real ocorreu no equinócio de outono, a maior no equinócio de primavera e a intermediária nos solstícios de verão e inverno. $\mathrm{O}$ ajuste menos eficaz do modelo foi encontrado para o verão e primavera, em que são observadas as maiores médias dos erros e desvios-padrão. $\mathrm{O}$ ajuste mais eficaz do modelo foi encontrado para o solstício de inverno e equinócio de outono, sendo observadas as menores médias dos erros e desvios-padrão médios. 
TABELA 5. Médias dos valores reais $\left(\mathrm{R}_{\text {Greais }}\right)$ e estimados $\left(\mathrm{R}_{\mathrm{Gest}}\right)$ da irradiação solar global, médias dos erros $(|\Delta|)$ e desvios-padrão médios $(\mathrm{S})$, para partição sazonal.

\begin{tabular}{cccccc}
\hline Média dos Dias Observados & Estações & $\mathrm{R}_{\text {Greais }}\left(\mathrm{MJ} \mathrm{m}^{-2}\right)$ & $\mathrm{R}_{\text {Gest }}\left(\mathrm{MJ} \mathrm{m}^{-2}\right)$ & $|\Delta|(\%)$ & $\mathrm{S}(\%)$ \\
\hline 89 & Primavera & 15,76 & 15,58 & 5,47 & 6,91 \\
91 & Verão & 15,52 & 14,61 & 6,99 & 5,10 \\
93 & Outono & 11,00 & 11,01 & 3,53 & 2,59 \\
93 & Inverno & 11,35 & 11,46 & 3,81 & 2,94 \\
\hline
\end{tabular}

Na Figura 1, apresenta-se a distribuição de freqüência dos erros médios diários para o período da validação do modelo. As maiores variações dos erros ocorreram no equinócio de primavera (Figura 1a), na qual é observada amplitude de $-19,45 \%$ a $27,98 \%$, havendo maior concentração dos erros no intervalo de -10 a $10 \%$, menores no outono e inverno com amplitude de $-11,32 \%$ a $10,61 \%$ e $-10,07 \%$ a 14,01\% (Figuras 1c e 1d), respectivamente, e intermediárias no verão, com intervalo de $-12,93 \%$ a 20,31\% (Figura 1b), confirmando os resultados obtidos anteriormente quando da análise da Tabela 5. O modelo possui tendência em subestimar a irradiação solar global para a primavera e verão e superestimar para o outono e inverno.

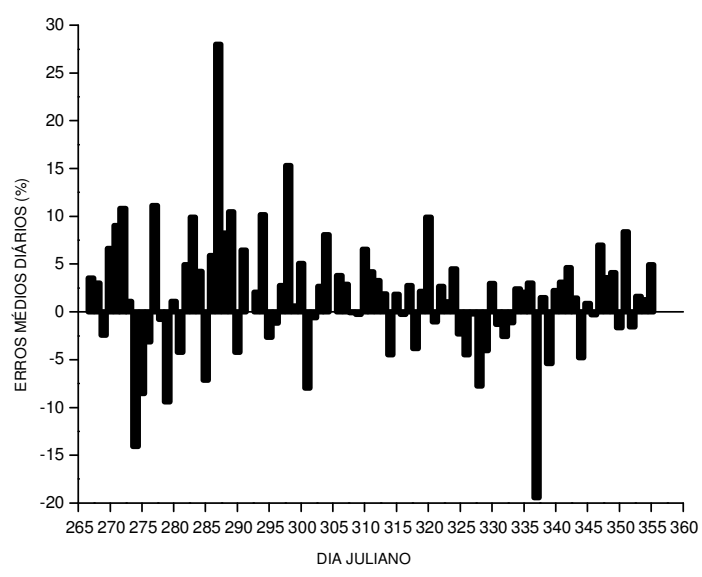

(a)

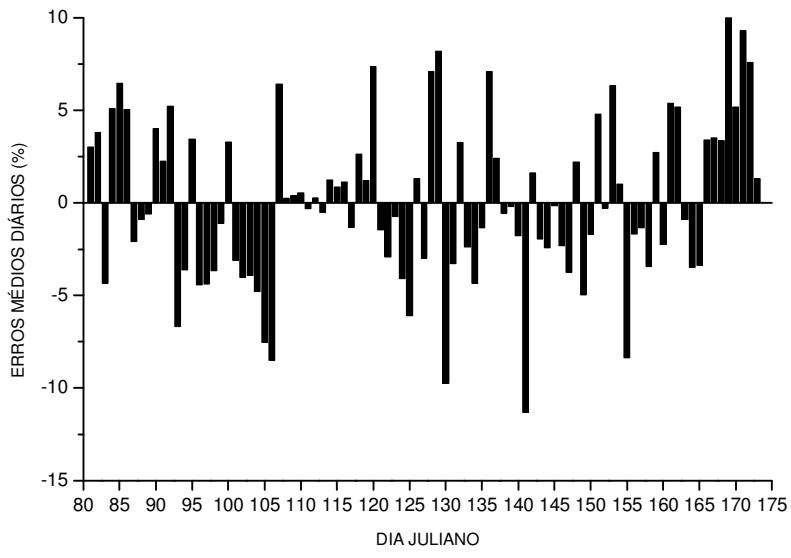

(c)

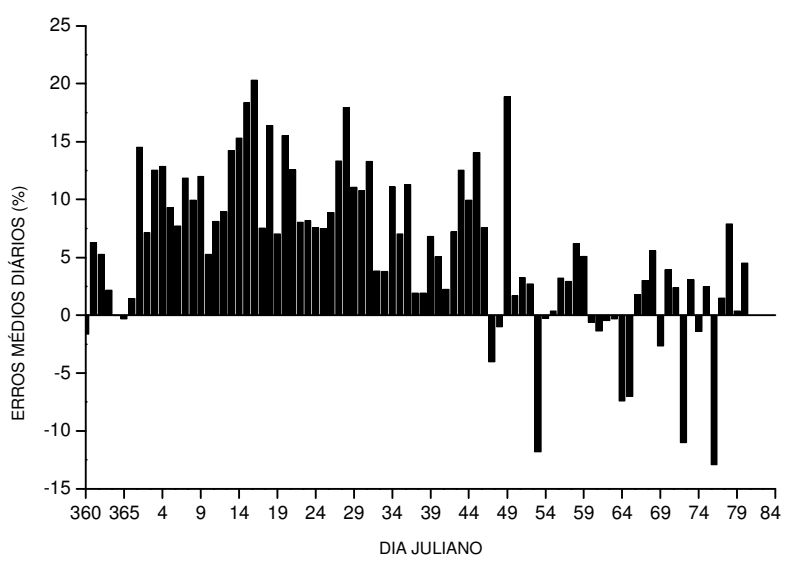

(b)

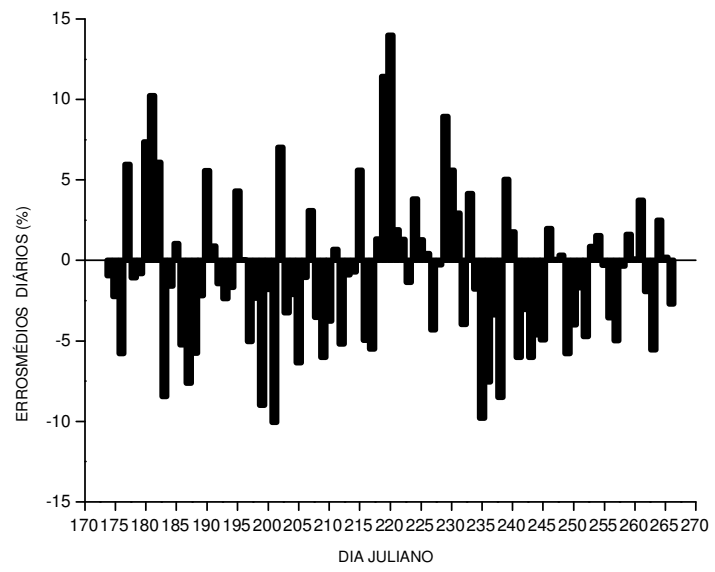

(d)

FIGURA 1. Distribuição de freqüência dos erros médios diários para o período de 1995 a 1998 para: a) primavera; b) verão; c) outono, e d) inverno. 


\section{Partição mensal}

$\mathrm{Na}$ Tabela 6, são apresentadas as médias dos valores reais $\left(\mathrm{R}_{\text {Greais }}\right)$ e estimados $\left(\mathrm{R}_{\text {Gest }}\right)$ da irradiação solar global, médias dos erros $(|\Delta|)$ e desvios-padrão médios $(\mathrm{S})$ para o período de validação do modelo.

TABELA 6. Médias dos valores reais $\left(\mathrm{R}_{\text {Greais }}\right)$ e estimados $\left(\mathrm{R}_{\mathrm{Gest}}\right)$ da irradiação solar global, médias dos erros $(|\Delta|)$ e desvios-padrão médios $(S)$ para a partição mensal.

\begin{tabular}{cccccc}
\hline $\begin{array}{c}\text { Médias dos Dias } \\
\text { Observados }\end{array}$ & Meses & $\mathrm{R}_{\text {Greais }}\left(\mathrm{MJ} \mathrm{m}^{-2}\right)$ & $\mathrm{R}_{\mathrm{Gest}}\left(\mathrm{MJ} \mathrm{m}^{-2}\right)$ & $|\Delta|(\%)$ & $\mathrm{S}(\%)$ \\
\hline 31 & janeiro & 16,38 & 15,34 & 7,02 & 7,99 \\
29 & fevereiro & 15,31 & 15,00 & 4,15 & 3,80 \\
31 & março & 13,45 & 13,36 & 4,03 & 3,32 \\
30 & abril & 12,20 & 11,73 & 4,48 & 2,94 \\
31 & maio & 10,28 & 10,37 & 4,21 & 3,44 \\
30 & junho & 8,95 & 8,99 & 3,87 & 2,33 \\
31 & julho & 10,47 & 10,62 & 3,89 & 3,22 \\
31 & agosto & 11,63 & 11,54 & 4,74 & 3,43 \\
30 & setembro & 12,88 & 12,67 & 4,13 & 3,27 \\
31 & outubro & 14,68 & 14,34 & 5,91 & 5,67 \\
30 & novembro & 16,84 & 16,45 & 3,43 & 2,40 \\
31 & dezembro & 17,42 & 16,93 & 4,62 & 2,77 \\
\hline
\end{tabular}

A maior e a menor incidências da irradiação solar global estimada e real foram observadas para dezembro e junho, respectivamente. O ajuste mais eficaz do modelo ocorreu em novembro e junho, e o menos eficaz em janeiro, em que foram observados os menores e maiores valores das médias dos erros e desvios-padrão médios, respectivamente.

Na Figura 2, mostra-se a distribuição de freqüência dos erros médios diários para o período de validação do modelo. As maiores variações dos erros ocorreram em janeiro (Figuras 2a), variando no intervalo de $-10,72 \%$ a $31,53 \%$ e menores para abril, com variação no intervalo de $-3,89 \%$ a $12,15 \%$ (Figura 2d), confirmando as observações anteriores na análise da Tabela 6. Para os demais meses, as variações foram de $-11,25 \%$ a $15,04 \%$ fevereiro; de $-13,03 \%$ a $9,21 \%$ para março; de $-12,96 \%$ a $13,17 \%$ para maio; de $10 \%$ a $6,94 \%$ para junho; de $-10,07 \%$ a $13,97 \%$ para julho; de $-8,41 \%$ a $15,08 \%$ para agosto; de $-11,25 \%$ a $12,86 \%$ para setembro; de $-9,29 \%$ a $29,16 \%$ para outubro; de $-6,19 \%$ a $10,91 \%$ para novembro, e de $-10,15 \%$ a $9,90 \%$ para dezembro. A irradiação solar global é subestimada para janeiro, fevereiro, março, abril, agosto, setembro, outubro, novembro e dezembro, e superestimada para maio, junho e julho.

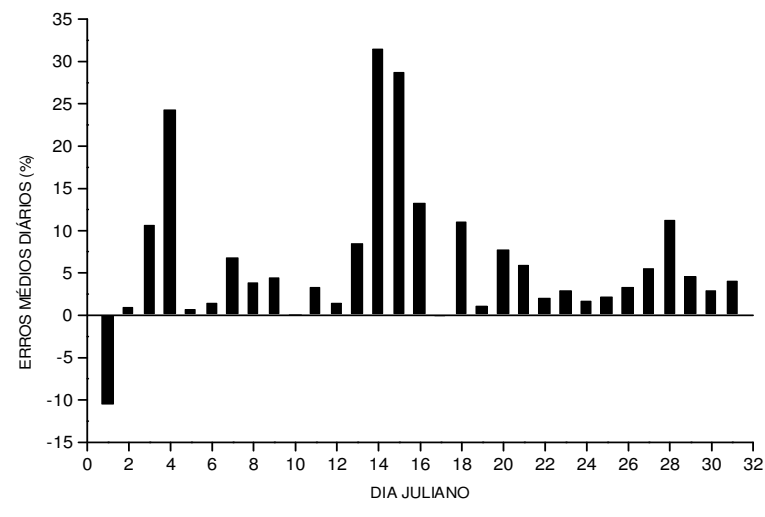

(a)

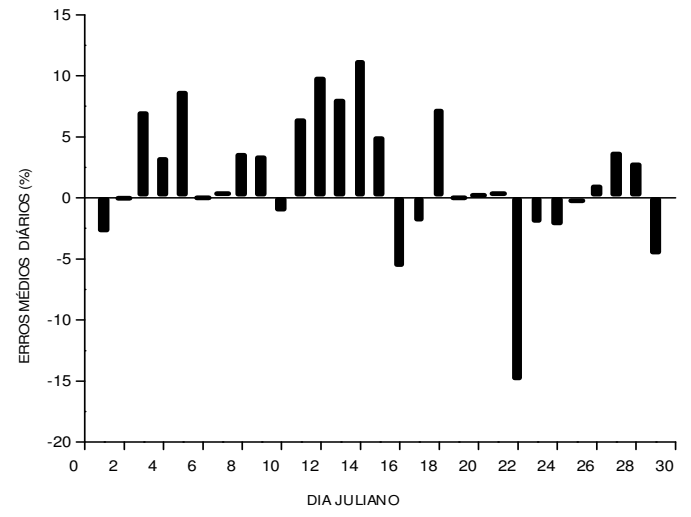

(b) 


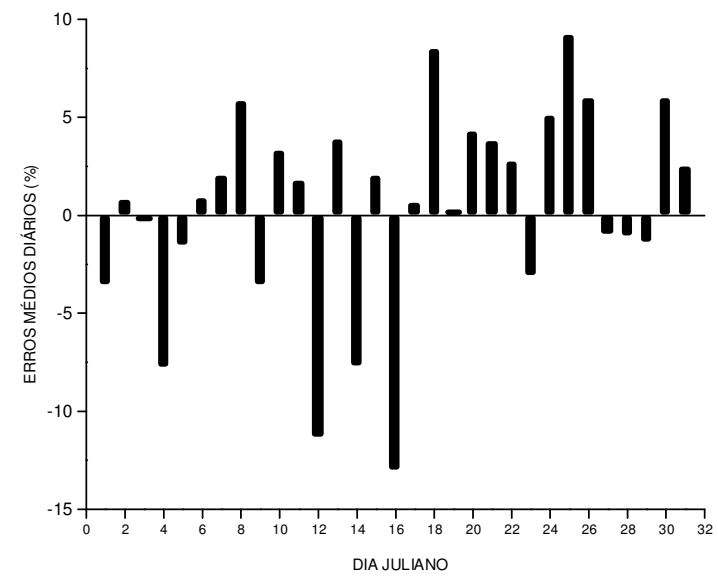

(c)

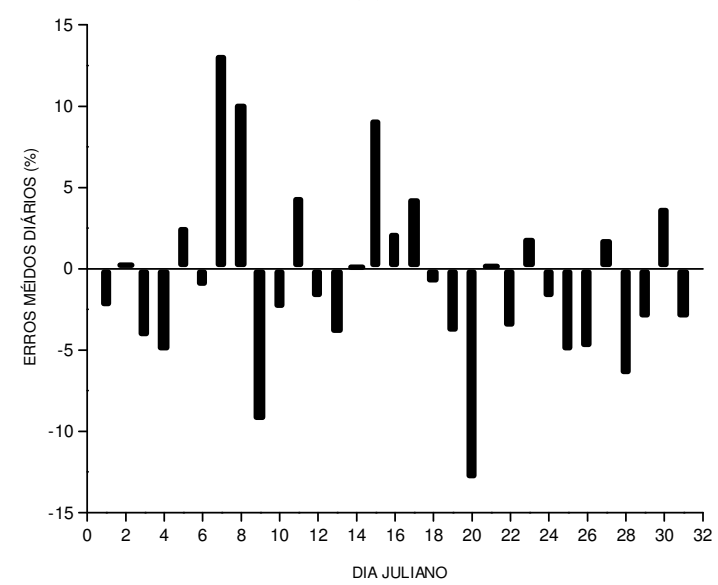

(e)

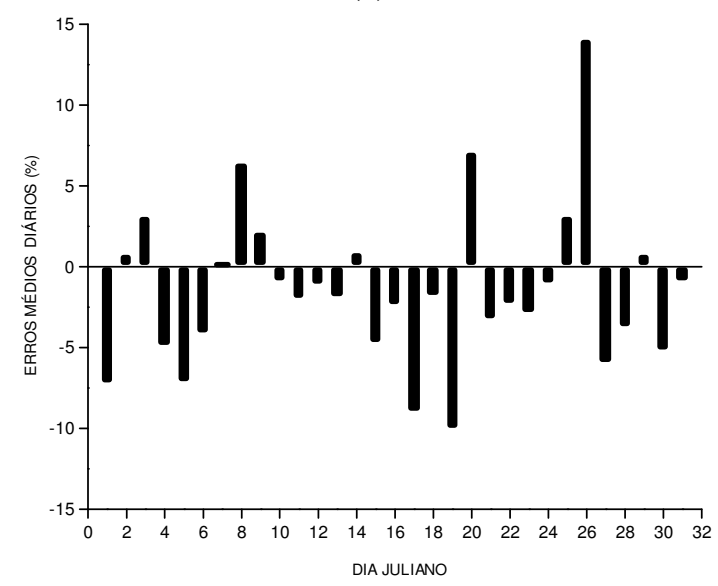

(g)

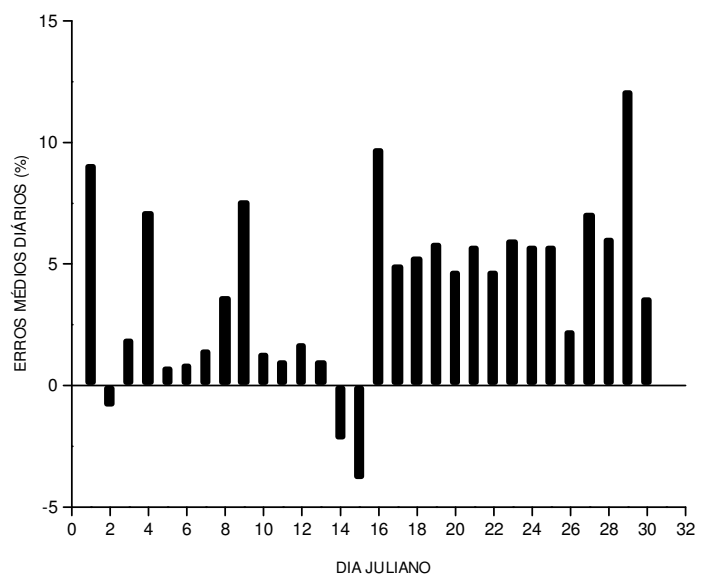

(d)

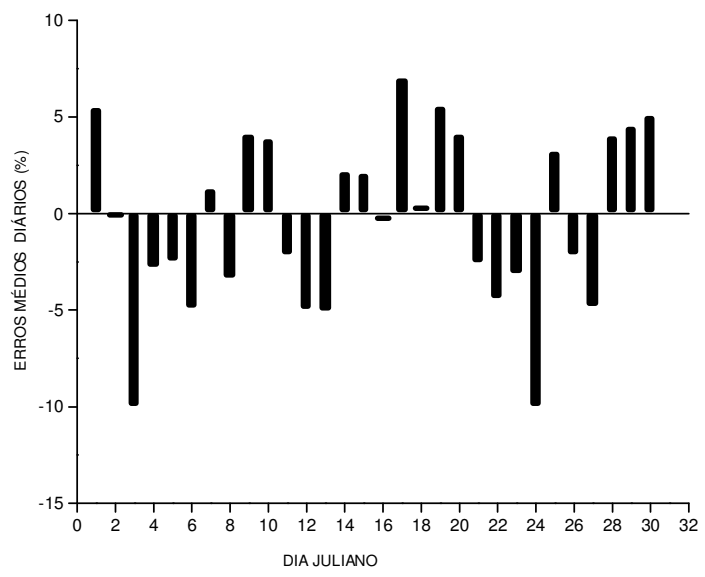

(f)

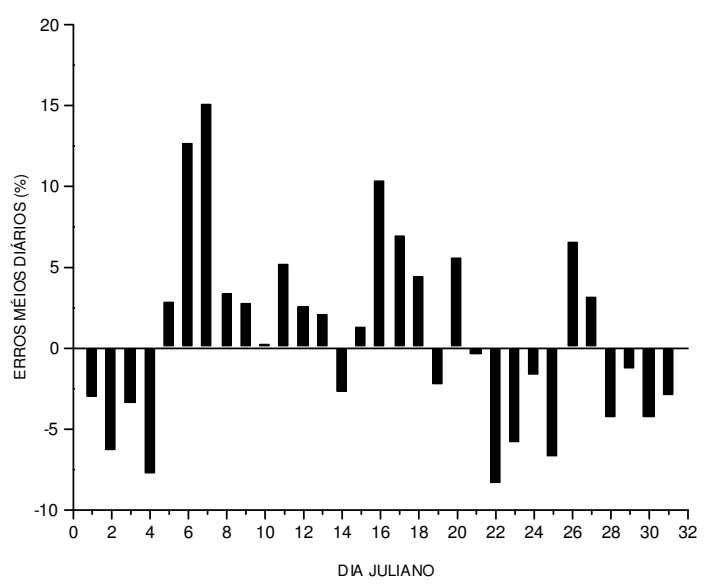

(h) 


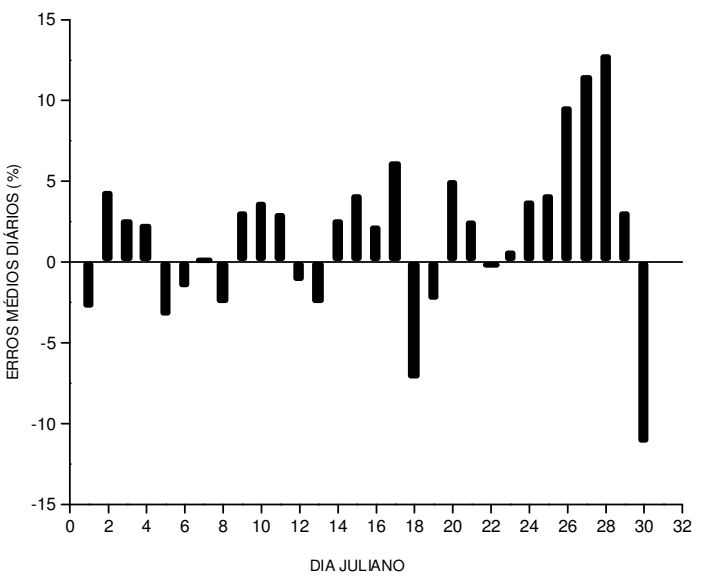

(i)

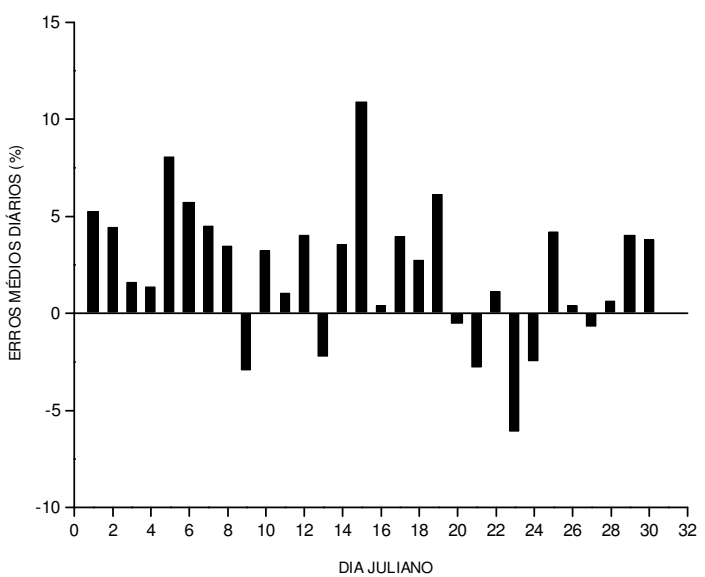

(k)

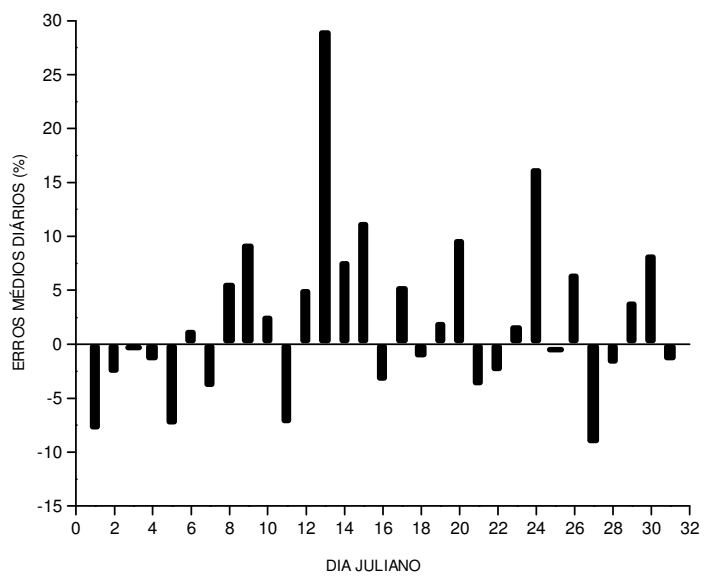

(j)

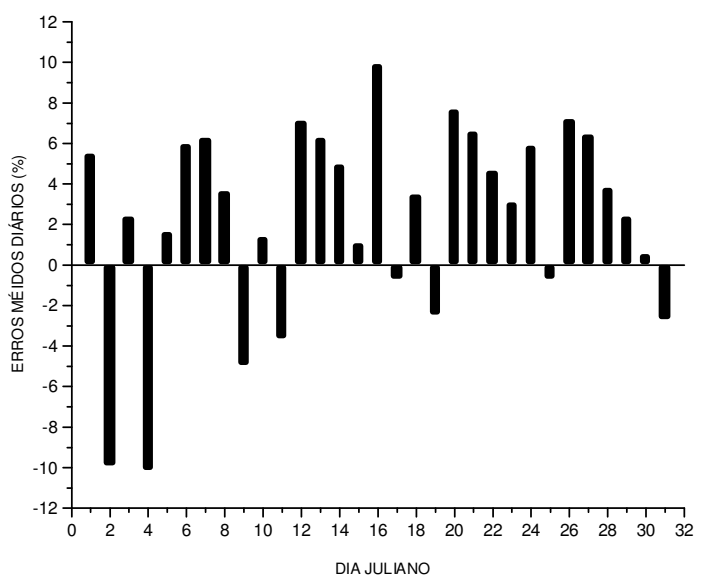

(1)

FIGURA 2. Freqüência dos erros médios diários obtidos na validação do modelo para: a) janeiro; b) fevereiro; c) março; d) abril; e) maio; f) junho; g) julho; h) agosto; i) setembro; j) outubro; k) novembro, e l) dezembro.

\section{CONCLUSÕES}

Ocorreu menor variação do coeficiente "a" $(0,16$ a 0,19$)$ e maior do coeficiente "b" $(0,34$ a 0,43$)$ para as duas partições.

O índice de claridade variou de $15 \%$ a $58 \%$ e $14 \%$ a $58 \%$ para as partições sazonal e mensal, respectivamente.

As maiores variações dos erros médios diários para a partição sazonal ocorreram no equinócio de primavera $(-19,45 \%$ a $27,28 \%)$ e as menores no equinócio de outono $(-11,32 \%$ a $10,61 \%)$, e para a partição mensal, nos meses de janeiro $(-10,72 \%$ a $31,53 \%)$ e abril $(-3,89 \%$ a $12,15 \%)$, respectivamente.

O ajuste mais eficaz das equações foi encontrado para a partição mensal.

\section{REFERENCIAS}

ANGSTROM, A. Solar and terrestrial radiation. Quarterly Journal of Royal Meteorological Society, Berks, v.50, n.1, p.121-5, 1924. 
CARDON, D.A.; AMORIN NETO, M.S. Relação entre radiação solar global e a insolação na região de Petrolina (PE). In: CONGRESSO BRASILEIRO DE AGROMETEOROLOGIA, 3., 1983, Campinas. Anais... Santa Maria: Sociedade Brasileira de Agrometeorologia, 1983. p.50-3.

CURY-LUNARDI, D. M.; CATANEO, A. Estimativa da radiação solar global diária para Botucatu, São Paulo. Científica, São Paulo, v.22, n.1, p.117-21, 1994.

DAL PAI, A.; ESCOBEDO, J. F. Modelo de estimativa da radiação solar difusa instantânea. In: SIMPÓSIO EM ENERGIA NA AGRICULTURA, 1., 1999, Botucatu. Anais... Botucatu: UNESP, 1999. v.2, p.312-17.

DANTAS, R.T.; CARNEIRO, G. M.; MELO, E. C. de S.; SOARES, D. B. Determinação dos coeficientes da equação de Angstrom para estimativa da irradiação solar global em dois municípios da Paraíba. In: CONGRESSO BRASILEIRO DE AGROMETEOROLOGIA, 11., REUNIÃO LATINOAMERICANA DE AGROMETEOROLOGIA, 2., 1999, Florianópolis. Anais... Santa Maria: Sociedade Brasileira de Agrometeorologia, 1999. p.2399-2403.

IQBAL, M. An introduction to solar radiation. New York: Academic Press, 1983. 387 p.

LAPERUTA FILHO, J. Modelos horários para estimativa da radiação solar global diária e horária em Botucatu. 1996. 117 f. Tese (Doutorado em Energia na Agricultura) - Universidade Estadual Paulista, Faculdade de Ciências Agronômicas, Botucatu, 1996.

PRESCOTT, J.A. Evaporation from a water surface in relation to solar radiation. Transactions of Royal Society of Science Austria,London, v.64, n.1, p.114-18, 1940.

RICIERI, P.R.; ESCOBEDO, F.J.; MARTINS, D. Relações das radiações solar difusa e global em Botucatu. In: CONGRESSO BRASILEIRO DE METEOROLOGIA, 9., 1996, Campos do Jordão. Anais...Rio de Janeiro: Sociedade Brasileira de Meteorologia, 1996. p.547-50.

RICIERI, R.P. Modelos de estimativa e avaliação dos métodos de medida da radiação solar difusa. 1998. 81 f. Tese (Doutorado em Energia na Agricultura) - Universidade Estadual Paulista, Faculdade de Ciências Agronômicas, Botucatu, 1998.

SANTOS, R.; ANDRE, R.G.B.; VOLPE, C.A. Estimativa da Radiação solar global em Jaboticabal, SP. Científica, São Paulo, v.11, n.1, p.31-9, 1983.

TUBELIS, A. Meteorologia descritiva: Fundamentos e aplicações brasileiras. São Paulo: Nobel, 1988. 374 p.

VALIATI, M.I.; RICIERI, R.P.; SANTOS, R.F. Modelo de estimativa da irradiação solar global para região de Cascavel. In: SIMPÓSIO DE ENERGIA NA AGRICULTURA, 1., 1999, Botucatu.

Anais...Botucatu: UNESP, 1999. v.2, p.395-402. 